\title{
Resenha: \\ Como sobreviver na sociedade líquida?
}

Diego Pereira ${ }^{1}$

Última obra de Umberto Eco (1932-2016), "Pape Satàn Aleppe: crônicas de uma sociedade líquida" (2017), ou, em italiano, sua versão original, "Pape Sàtan Allepe: cronache di uma societá liquida" (2016), reúne algumas de suas crônicas publicadas na coluna que mantinha, desde 1985, na revista L'Espresso — todas correspondentes a "[...] breves anotações e divagações sobre os mais variados temas [...] - em geral, inspirados na atualidade" (ECO, 2017[2016], p. 7). O próprio título de sua coluna, uma alusão às "caixinhas de fósforos Minerva", cujo interior "oferecia dois espaços em branco, nos quais era possível tomar notas" (ECO, 2017[2016], p. 7), sugere esse objetivo. De lá para cá, boa parte dessa produção foi recuperada pelo autor em quatro compilações: algumas daquelas originalmente publicadas entre 1985 e o início da década de 90 encontram-se em $\mathrm{Il}$ secondo diario minimo (1992); entre a década de 90 e o início dos anos 2000, em La Bustina di Minerva (2001) e A passo di gambero (2006); e, entre 2000 e 2015, no livro objeto desta resenha, não por acaso publicado sob o título principal Pape Satàn Aleppe (2016). Essas palavras, extraídas de um verso d'A Divina Comédia, servem a Eco (2017[2016]) justamente por seu significado difuso, também explorado no poema dantesco: "confundem as ideias e podem se prestar a qualquer diabrura" (ECO, 2017[2016], p. 8). E, conforme ele mesmo confessa, a citação traduz sua "coletânea que [...] é desconexa, vai do galo ao asno [...] e reflete a natureza líquida destes quinze anos [2000-2015]” (ECO, 2017[2016], p. 8) — a costura que permite o alinhavo dessas suas crônicas, agora republicadas.

Especialmente em "Pape Satàn Aleppe: crônicas de uma sociedade líquida", os temas abordados por Eco (2017[2016]) são aqueles de interesse à sociedade contemporânea, que, nem sempre ciente de sua liquefação/liquidez, ou seja, de sua precarização diante da crise das ideologias e dos partidos, precisa compreender a si mesma para superar-se, sob pena de servir a propósitos político-econômicos escusos. Neste caso, o autor alude a Bauman, ou melhor, à sua ideia de modernidade/sociedade líquida, que, além de explicitada na primeira crônica ("A sociedade líquida"), é apontada como elemento-chave para o reconhecimento da tese central do livro: viver o presente nascente implica enfrentar não apenas as crises que lhe constituem (como a de Estado, a das ideologias e dos partidos e a do apelo à comunidade de valores), mas a si próprio, opondo-se ao individualismo e ao consumismo desenfreados a que se acaba constantemente exposto e, por vezes, influenciado - isto é, se se objetiva escapar dos "caciques políticos ou chefes mafiosos que controlam votos" (ECO, 2017[2016], p. 10).

Todas as 175 crônicas, com exceção da primeira, que o autor destaca por razões prefaciais, distribuem-se em catorze seções e convidam à essa reflexão sobre a modernidade recente, da implicação de seus aspectos à sociedade contemporânea; embora a variedade de motivos (político-econômicos, histórico-culturais, linguístico-literários, etc.) e, muitas vezes, sua circunscrição histórico-geográfica (a Itália e a Europa, com seus inimigos internos), para além de uma abordagem irônica (mais expressa em alguns textos, me-

1 Mestrando pelo Programa de Pós-Graduação em Linguística Aplicada da Universidade Estadual de Campinas (UNICAMP). 
nos, em outros), não evidenciem, de imediato, tal convite, ou, talvez, o inviabilizem, a qualquer leitor que não o especializado (em geral, o pesquisador, notadamente, aquele das ciências humanas) e/ou o italiano/europeu (tamanha sua familiaridade com os fatos abordados). De todo modo, a primeira seção, "A passo de caranguejo", acaba sendo um pórtico da obra e, nesse sentido, parece contribuir ao estabelecimento de seu fio condutor, até mesmo pela temática enfocada, reiterada nas seções seguintes, a saber: algumas das transformações histórico-culturais pelas quais tem passado a sociedade, nos campos da ciência e da religião, informação e tecnologia, e, da cidadania e política; de seus avanços e retrocessos, que, dada a preocupação do autor, precisam/devem ser desvelados por quem vive o seu influxo.

Aqui, importam três constatações de Eco (2017[2016]), ou que são por ele incitadas. Primeira: a ciência, com seu ideal de progresso, não é mais comum a liberais e a socialistas, nem mesmo entre os membros de cada um desses grupos, compostos tanto por apoiadores do desenvolvimento tecnológico quanto por apoiadores do "retorno à Tradição e à Natureza incontaminada das origens" (ECO, 2017[2016], p. 15). Difusão de fronteiras essa expressa também "na oposição entre mundo religioso e mundo laico" (ECO, 2017[2016], p. 16), quando princípios antes próprios da vida laica são adotados por aqueles de vida religiosa e vice-versa. Segunda: toda e qualquer invenção, tradutora do avanço informacional-tecnológico, é/deve ser passível de questionamento, especialmente quanto ao seu papel político-social no cotidiano da humanidade; por haver, sempre, invenções úteis/inúteis e, em ambos os casos, inócuas/nocivas. Ao que "o progresso não consiste necessariamente em ir sempre adiante a qualquer custo" (ECO, 2017[2016], p. 19), "existem progressos tecnológicos além dos quais não se pode ir" (ECO, 2017[2016], p. 21) e “[...] o progresso também pode significar dar dois passos atrás [...]." (ECO, 2017[2016], p. 21). Terceira: A história é um continuum, razão pela qual os fatos do passado não só repercutem no presente, mas, neste tempo, podem acabar reavivados, a despeito de qualquer avanço já experimentado pela sociedade ou, inclusive, por causa dele.

Nas seções "Ser vistos" (seção 2), "Os velhos e os jovens" (seção 3), "On-line” (seção 4) e "Sobre os celulares" (seção 5), por exemplo, Eco (2017[2016]) não apenas aponta alguns dos fenômenos próprios da sociedade líquida, "na qual todos estão em crise de identidade e de valores e não sabem buscar os pontos de referência para definir-se", mas suas principais implicações àqueles nascidos há uma, duas ou três gerações, sugerindo-lhes reflexões filosóficas, para a melhor compreensão do éthos a que, agora, todos estão submetidos. Segundo o autor, vive-se hoje: 1) a visibilidade enquanto bem natural e primário da vida, propulsora da busca pelo reconhecimento a qualquer custo; 2) a ânsia pela aparição midiática, substituta de toda e qualquer experiência transcendental, aquela que se sobrepõe às ideias e aos conhecimentos ordinários; 3) a renúncia ao pudor, "sentimento zeloso da própria privacidade" (ECO, 2017[2016], p. 35), e a negligência da reputação pública, para a obtenção de notoriedade; 4) a esgarçadura do pensamento expresso nas redes sociais virtuais, que, aparentemente dialógico, sensato, socialmente comprometido e, por isto, sólido, concorre com um dos grandes objetivos das plataformas nas quais se inscreve, como o de "fidelizar uma grande quantidade de usuários da web" (ECO, 2017[2016], p. 37); 5) a vigilância, ou o controle, de pensamentos e emoções alheios exercida sobre a sociedade por aqueles que a constituem - mais ainda, pelas "agências ligadas aos centros de poder" (ECO, 2017[2016], p. 37); e, 6) o triunfo da "libidinosa satisfação com a desgraça ou a dor alheia” (ECO, 2017[2016], p. 40), celebrado na opinião pública. 
Esse, inclusive, é um dos saldos da conectividade global, que, potencializada pelas tecnologias digitais da informação e da comunicação, induz, de certo modo, a contração da memória num eterno presente, o que Eco (2017[2016]) denomina "achatamento do passado no presente" ou "eclipsamento da dimensão histórica". Não por acaso, o indivíduo experimenta cada vez mais a superestimação de si, acompanhada do sentimento de completude e infalibilidade; e, a sociedade, sua alienação histórico-cultural, política porque a própria mudança dos saberes e das práticas é condicionada à educação pela publicidade (mesmo as manifestações mais superficiais são enraizadas pela mídia). Com isso, é claro, o autor não se pretende apocalíptico. Em suas palavras, "[...] esconder-se do mundo, exilar-se no deserto, sepultar-se num claustro [...] já aconteceu no ocaso de uma era, quando os imperadores começaram a transformar seus próprios cavalos em senadores" (ECO, 2017[2016], p. 31). Mas é chegada a hora de compreender como e por que: 1) o principal instrumento da comunicação do novo milênio não [...] [é] capaz de instaurar e controlar a observância [...] [do pacto da veracidade]" (ECO, 2017[2016], p. 72); 2) "numa democracia, [...] os governantes são controlados pela imprensa, pelos grupos de pressão, pela opinião pública" (ECO, 2017[2016], p. 74); 3) a aceleração do desenvolvimento tecnológico serve a interesses do sistema; 4) permite-se, através do uso das novas tecnologias digitais da informação e da comunicação, o monitoramento do próprio comportamento/pensamento; 5) na era da internet, importa, à cultura, a distinção entre acúmulo e seleção/discriminação; e, 6) "exceto em casos excepcionais, o problema do virtual não diz respeito aos insanos, mas aos sãos" (ECO, 2017[2016], p. 97). Em meio a esse debate, mesmo uma pergunta como "Ainda é possível viver sem celular?" requer atenção, visto que "nem sempre a transformação coincide com a emancipação" (ECO, 2017[2016], p. 106).

Nesse sentido, a próxima seção (seção 6), "Sobre as conspirações", tem também um papel destacável, ao tratar do direcionamento, perigoso, da imaginação pública, por meio de conspirações e paranoias que, disseminadas ad nauseam, propõem-se à reinterpretação dos acontecimentos da história, desresponsabilizando os seus principais agentes, como a sociedade em si e as instituições que a representam. Esquadrinhando a psicologia da conspiração, Eco (2017[2016]) alerta para os riscos da interpretação suspeitosa a que fatos da vida cotidiana acabam submetidos, especialmente por força dos meios de comunicação de massa, cuja história não permite profecias, mas admite ponderações - como o faz na seção 7, "Sobre os mass media". Nesta, uma das seções de maior variedade temática, três constatações parecem sobrepor-se às demais. Primeira: "[...] estamos vivendo amplamente realidades virtuais. Conhecemos o mundo através da televisão, que muitas vezes não o retrata tal como é, mas trata de reconstruí-lo [...] ou até de construí-lo novamente [...]” (ECO, 2017[2016], p. 144). Segunda: “[...] uma mensagem visa certos efeitos, mas pode confrontar-se com situações locais, com diferentes disposições psicológicas, desejos, medos, e produzir um efeito bumerangue" (ECO, 2017[2016], p. 153). E, terceira: "[...] se alguém detém o controle das emissoras, não é possível ocupar a primeira cadeira diante das câmeras, mas podemos ocupar idealmente a primeira cadeira diante de cada televisor" (ECO, 2017[2016], p. 154). Nesta nova era, inclusive, em que se achincalha disparatadamente a escola, sobretudo a pública, por sua presumida ineficiência/ineficácia diante dos novos desafios socioeducativos, até esse retrato, ou ele em especial, carece de problematização, pois, como defende o autor: 
[...]. É claro que as coisas que acontecem no Iraque aparecem na TV, mas o motivo pelo qual certas coisas acontecem sempre lá, desde os tempos da civilização mesopotâmica, e não na Groenlândia, é algo que só a escola pode dizer. E se alguém argumentasse que muitas vezes essas explicações são dadas por pessoas até bastante autorizadas no talk show Porta a porta, diria que a escola deve discutir o Porta a porta. (ECO, 2017[2016], p. 88).

Assim, começar pela atenção a fatos geopolíticos nacionais/internacionais (que, em maior ou menor medida, interferem na dinâmica histórico-cultural dos países, independentemente de quantos e quais sejam), sob o compromisso de refleti-los filosoficamente, mostra-se uma alternativa viável à sociedade e à escola pós-moderna no combate à suposta alienação política da primeira. As seções "Várias formas de racismo" (seção 8), "Sobre o ódio e a morte" (seção 9) e "Entre religião e filosofia" (seção 10) provam isso. Na primeira dessas três, eis alguns fenômenos observados por Eco (2017[2016]): 1) a suposta ancoragem da opinião pública ocidental no antissemitismo que, de base religiosa, popular e/ou científica, tem, nesta última, sua expressão máxima, traduzindo-se, em todas elas, em um conjunto de "comportamentos irracionais e cegamente fidelistas" (ECO, 2017[2016], p. 197); 2) o pensamento extremista na alimentação do antissemitismo e/ ou do racismo; e, 3) a coexistência de guerras externas a um ou mais povos, por "reivindicações territoriais, ódios étnicos, repetidas violações de fronteiras, e assim por diante" (ECO, 2017[2016], p. 202), e guerras internas, que, no caso da Itália (e, talvez, de outras nações), expressa-se na disputa

cidade contra cidade, hereges contra ortodoxos, depois classe contra classe, partido contra partido, corrente de partido contra corrente do mesmo partido, em seguida região contra região e, por fim, governo e magistratura, magistratura e poder econômico, televisão pública contra televisão privada, aliados de coalisão contra aliados da mesma coalisão, departamento contra departamento, jornal contra jornal (ECO, 2017[2016], p. 202).0

É possível que todos esses fatos, inter-relacionáveis, encontrem seu motivo nas crônicas de "Sobre o ódio e o amor", nas quais o autor (ECO, 2017[2016], p. 223) discute o "racismo", a "construção do inimigo" e a "função política do ódio pelo Outro ou pelo Diferente". E, se para alguns, de relativismo radical, "não existem fatos, apenas interpretações" (ECO, 2017[2016], p. 250), ou, para outros, de uma obviedade só, "conhecemos todos os fatos através de nossa interpretação" (ECO, 2017[2016], p. 250), para Eco (2017[2016]), “a presença dos fatos é demonstrada pelo fato de que algumas interpretações realmente não funcionam e, portanto, deve existir alguma coisa que nos obriga a descartá-las (ECO, 2017[2016], p. 250)" — já que “os fatos são aquelas coisas que, assim que os interpretamos de modo equivocado, nos dizem que não iremos adiante se insistirmos nesse caminho" (ECO, 2017[2016], p. 252). "Entre religião e filosofia", sua lição está clara: se não existissem respostas filosóficas a perguntas do gênero "(i) como compreender o mundo onde estamos, (ii) qual é a natureza da realidade [...], nem mesmo o físico poderia dizer por que conhece e o que conhece" (ECO, 2017[2016], p. 268).

Por isso, ao tratar sobre "A boa educação" (seção 11), discutindo desde a dificuldade e o perigo subjacentes ao estabelecimento de "critérios de excelência em bases quantitativas [...] e elementos qualitativos" (ECO, 2017[2016], p. 279) - especialmente, quanto ao ensino superior — até as implicações de um ensino básico simplista/reducionista à socie- 
dade, hoje mais exposta a um éthos fundamentalista, neoconservador e reacionário, Eco (2017 [2016]) sugere a importância da educação do pensamento e da ação: ela deve servir não somente para o belo e o bem-estar social, mas, também, para "lidar com a história e com a memória" (ECO, 2017[2016], p. 295). Afinal, como parece justificar mais adiante, em "Sobre livros e outras coisas mais" (seção 12), "nosso saber (mesmo o científico e não apenas o mítico) é um tecido de histórias" (ECO, 2017[2016], p. 308) por meio do qual se propaga - com o agravante de que "A história é lodosa e viscosa. Algo que é bom ter sempre em mente, pois as catástrofes de amanhã sempre estão maturando desde hoje, furtivamente" (ECO, 2017[2016], p. 321).

Sua preocupação com o declínio e a queda de "A Quarta Roma" (seção 13), "um imponente network composto por um grande império central e um arquipélago de reinos federados" (ECO, 2017[2016], p. 341), correspondente aos impérios do Ocidente do século $\mathrm{XX}$, introduz alguns dos fenômenos cuja história convém (re)conhecer/problematizar no século atual: 1) o assentamento de regimes governamentais na "identidade de interesses entre a própria vida (e interesses privados) [de determinados políticos] e o Estado" (ECO, 2017[2016], p. 345); 2) a transversalidade dos temas dos debates políticos a comportamentos como o conservador, reacionário, fascista etc.; 3) a instauração do populismo midiático na condução política das nações; 4) a aplicação flexibilizada das Leis, favorável a uns grupos políticos e desfavorável a outros; e, 5) a substituição do "debate entre duas partes que [, num processo,] apresentam provas e contraprovas [...] [pelo] duelo midiático" (ECO, 2017[2016], p. 375). Na última seção, "Da estupidez à loucura" (seção 14), Eco (2017[2016]) arremata: "Hoje, ninguém mais pretende [...] que os Estados sejam governados pelos filósofos, mas seria muito bom se estivessem nas mãos de pessoas com ideias claras" (ECO, 2017[2016], p. 381) - "o mundo tornou-se uma coisa complicada demais para ser governado por quem o governou até agora" (ECO, 2017[2016], p. 388). Instrutivo, seu pensamento não é uma armadilha: "leve ao extremo as teses alheias e uma gargalhada será sua lápide" (ECO, 2017[2016], p. 415).

Nisso, inclusive, reside o grande mérito de "Pape Satàn Aleppe: crônicas de uma sociedade líquida": incitar seu leitor — que se inscreve na pós-modernidade ou na modernidade tardia e, por conseguinte, está à mercê do éthos característico dessa era — ao questionamento de si e do outro, enquanto ambos constroem, ou servem à construção, do próprio mundo, em um dado contexto histórico-social. Principalmente para que ele possa proceder à reflexão crítica de sua ação cultural sobre a realidade, compreendendo, por exemplo, as implicações, à sua história e à de sua época, de se agir como tradutor da sociedade da informação, se filiado ao seu sistema de crenças e valores, ou da sociedade do conhecimento. E, aqui, não há respostas; antes, perguntas. Quando, nesta que é a sua última obra, Eco [2017(2016)] enfrenta variados dilemas do presente nascente, sob facetas das mais diversas (político-econômica, socioeducativa, linguístico-cultural etc.), o faz, sobretudo, para que a sociedade contemporânea não decline desse desafio, talvez o maior por ela já enfrentado - o de superar-se. Por isso, suas crônicas devem ser lidas: pelo compromisso ético que assumem, embora despretensiosamente - o de universalizar a humanidade, seu desenvolvimento social. De certo, profissionais da educação tendem a se beneficiar mais dessa coletânea e das discussões por ela suscitadas. Afinal, a transformação dos saberes e das práticas que os dias atuais têm provocado acaba por requerer da escola a reconfiguração de seus papéis. 
PEREIRA, Diego

Referências

ECO, Umberto. Pape Satàn aleppe: crônicas de uma sociedade líquida. Rio de Janeiro: Record, 2017 [2016]. Tradução do italiano por Eliana Aguiar.

Recebido em: 07/08/2019; Aceito em: 30/08/2019 